\title{
PIGMENT EPITHELIOPATHY WITH SEROUS DETACHMENT OF THE RETINA FOLLOWING INTRAVENOUS IRON DEXTRAN
}

\author{
P. R. HODGKINS ${ }^{1}$, A. J. MORRELL ${ }^{2}$, A. J. LUFF $^{1}$, T. J. FETHERSTON ${ }^{3}$, P. GOOD \\ Southampton, Birmingham and Coventry
}

\begin{abstract}
SUMMARY
We report a case of pigment epitheliopathy with serious detachment of the retina in a 23-year-old man following a total dose infusion of iron dextran. Initial impairment of visual acuity resolved spontaneously, along with changes in the elctro-oculogram and fundus fluorescein angiogram. Ocular features of systemic iron toxicity are reviewed and the pathophysiology discussed. Practitioners using total dose iron infusion should be aware of the possible ocular complications.
\end{abstract}

As iron deficiency is common in chronic ambulatory peritoneal dialysis and oral iron supplementation frequently inadequate, prophylactic intravenous iron may be required. ' Administration of iron dextran was first by intramuscular and later by intravenous injection. Practical difficulties in the injection of large volumes of iron dextran led to the development of "total dose infusion", whereby the dose required, diluted to a solution of not more than $5 \%$ iron dextran, is given by continuous infusion over several hours.

Reports of ocular pathology following systemic iron therapy are few. A pigmentary retinal degeneration has been noted ${ }^{3}$ and the manufacturers of Imferon (intravenous iron dextran) are aware of one adverse reaction to a date-expired solution consisting of nausea, transient visual loss, muscle spasm and loss of consciousness (personal communication).

We report the case of a young man who developed pigment epitheliopathy with serous detachment of the retina following intravenous iron dextran.

'Southampton Eye Hospital, Wilton Avenue, Southampton SO9 4XW.

${ }^{2}$ Birmingham and Midland Eye Hospital, Church Street, Birmingham B3 2NS.

${ }^{3}$ Department of Ophthalmology, Coventry and Warwickshire Hospital, Stoney Stanton Lane, Coventry.

Correspondence to: Dr P. R. Hodgkins, Southampton Eye Hospital, Wilton Avenue, Southampton SO9 4XW.

\section{CASE REPORT}

A 23-year-old man with chronic renal failure secondary to glomerulosclerosis was admitted for his first "total dose infusion" of iron dextran in November 1990. Chronic ambulatory peritoneal dialysis had begun in 1986 and three unsuccessful renal tansplants had subsequently been performed. Erythropoietin therapy was commenced in September 1990, following which he developed iron deficiency.

Hypertension was diagnosed in 1983 but remained refractory to treatment, with pressures up to $230 \mathrm{mmHg}$ systolic and $130 \mathrm{mmHg}$ diastolic. Prior to the infusion, treatment was with enalapril $30 \mathrm{mg}$ od, atenolol $50 \mathrm{mg}$ od, nifedipine $10 \mathrm{mg}$ bd, testosterone $80 \mathrm{mg}$ od, calcium carbonate 1 capsule tds, ascorbic acid $100 \mathrm{mg}$ bd, ferrous sulphate SR $750 \mathrm{mg}$ od and erythropoeitin 2000 units 3 times per week.

Blood pressure on the day of infusion was initially 210/ $100 \mathrm{mmHg}$, falling to $170 / 100 \mathrm{mmHg}$ with oral nifedipine $10 \mathrm{mg}$ stat. As this pressure remained stable, a total dose iron infusion was given four hours later, $3 \mathrm{~g}$ of iron being given as $59.9 \mathrm{ml}$ iron dextran in $500 \mathrm{ml}$ normal saline. The blood pressure remained at pre-infusion levels, the patient was asymptomatic and discharged after one hour.

Blurring of vision, noticed whilst driving home, gradually worsened and he presented to the eye department 72 hours later. There was no past ocular history and acuities of $6 / 6$ in each eye had been recorded three months earlier.

On examination visual acuity was 6/60 right and 6/36 left. Pupil responses, anterior segments and intraocular pressures were normal. Fundoscopy revealed posterior multifocal pale lesions at the level of the retinal pigment epithelium in both eyes, with serous detachment of the overlying retina. Serum iron was $310 \mathrm{microm} / \mathrm{L}$ (reference 13-40) and ESR $150 \mathrm{~mm} / \mathrm{hr}$. Fundus fluorescein angiography four days later (Fig. 1) showed slow choroidal filling and leakage through multiple retinal pigment epithelial defects with pooling in the subretinal space. 
Over the next two weeks the vision returned to $6 / 6$ in each eye, the only remaining fundal abnormality being patchy depigmentation at the posterior poles. The serum iron concentration fell to eight micromol/L and the ESR to $64 \mathrm{~mm} / \mathrm{hr}$. Fluorescein angiography three months later showed recovery of choroidal perfusion with complete resolution of the pigment epitheliopathy.

\section{ELECTRODIAGNOSTIC TESTS}

At investigation one week post-infusion the EOG was reduced $-160 \%$ in the right eye and $148 \%$ in the left. The ERG was slightly reduced in the right eye to scotopic, photopic, flicker ( $30 \mathrm{~Hz}$ cone) and pattern stimuli. In the left eye the ERG was normal apart from a reduction in the N95 component of the pattern ERG. The visual evoked potentials from each eye was delayed to pattern stimulation (133 msec right and $126 \mathrm{msec}$ left).

At three months the EOG abnormalities had completely resolved (200\% right and 245\% left) but the ERGs were unchanged. The VEP from each eye had improved in amplitude and latency, although the right was still slightly delayed.

\section{DISCUSSION}

Pigment epitheliopathy with serous detachment of the retina has been described in young adults. It occupies an intermediate position between acute posterior multifocal placoid pigment epitheliopathy (APMPPE) and purely ocular Harada's Disease, probably reflecting a local choroidal vasculopathy with focal pigment epithelial infarction. ${ }^{4}$ The aetiology of these conditions is unknown, although APMPPE has been noted to follow viral infection. ${ }^{5}$

Pigment epitheliopathy has not previously been described in intravenous iron therapy but the timing of onset of visual symptoms in this case suggests a probable association. The most significant electrophysiological finding was the initial reduction and subsequent complete recovery of the EOG, mirroring the clinical appearance of the RPE. In drug toxicity or APMPPE the EOG is typically reduced but later recovers. The reduced VER may reflect a resolving maculopathy, although optic nerve or ganglion cell involvement could be implicated.

Abnormal EOGs have been observed with iron overload in siderosis ${ }^{6}$ and desferrioxamine therapy. ${ }^{7.8}$ This may be due to iron promoted oxidative damage to RPE apical cell membranes and photoreceptor outer segments, both of which are rich in long chain polyunsaturated fatty acids. ${ }^{6,7}$
The serum iron concentration has been reported to exceed the iron binding capacity of circulating transferrin soon after imferon infusion, producing bleomycin-iron. This initiates lipid peroxidation ${ }^{9}$ and catalyses oxidation of ascorbic acid and proteins. Such a mechanism may result in bleomycin-iron crossing the blood retinal barrier.

Other possible causes of pigment epitheliopathy include hypertension ${ }^{10}$ and direct iron toxicity. The hypertension in this case was long standing, and relatively well controlled prior to and during imferon infusion. Iron dextran contains $5 \%$ iron $(50 \mathrm{mg} / \mathrm{ml})$ in $20 \%$ dextran: The solution is a stable isotonic complex which does not dissociate to free ionic iron ${ }^{11}$, and is therefore unlikely to have a direct toxic effect.

The need for parenteral iron therapy is likely to increase with the expanding role of erythropoietin in chronic renal failure. Physicians should be aware of possible ocular toxicity.

\section{REFERENCES}

1. MacDougall IC, Hutton RD, Calvin I, Coles GA, Williams JD: Poor response to treatment of renal anaemia with erythropoietin corrected by iron given intravenously. $\mathrm{Br} \mathrm{Med} \mathrm{J}$ 1989 299: 157-8.

2. Basu SK: Rapid administration of iron dextran in late pregnancy. Lancet 1963 1: 1430.

3. Fraunfelder FT: Drug induced ocular side effects and drug interactions. 2nd Ed. Philadelphia: Lea \& Febiger, 1982 193-4.

4. Wright BE, Bird AC, Hamilton AM: Placoid pigment epitheliopathy and Harada's disease. Br J Ophthalmol 1978 62: 609-21.

5. Azur P, Gohd RS, Waltman D, Gitter KA: Acute posterior multifocal placoid pigment epitheliopathy associated with an adenovirus type 5 infection. Am J Ophthalmol 1975 80: 1003-5.

6. Good PA and Gross K: Electrophysiology and metallosis: support for an oxidative (free radical) mechanism in the human eye. Ophthalmologica 1988 196: 204-9.

7. Blake DR, Winyard P, Lunec J. et al: Cerebral and ocular toxicity induced by Desferrioxamine. $Q J$ Med 1985 219: 345-55.

8. Pall HS, Blake DR, Winyard P. et al. Ocular toxicity of Desferrioxamine-an example of copper promoted auto-oxidative damage. Br J Ophthamol 1989 73: 29-31.

9. Aust SD and Songen BA: The role of iron in enzymatic lipid peroxidation. In: Pryor WA ed. Free Radicals in Biology Vol 5 New York Academic Press 1982 1-28.

10. Klein BA: Ischaemic infarcts of the choroid (Elschnig spots) Am J Ophthalmol 1968 66: 1069-74.

11. Cox JSG. King PE, Reynolds GF: Valency investigations of iron dextran (imferon) Nature 1965, 207: 1202. 